\title{
Article
}

\section{D BIM for Construction Logistics Management}

\author{
Kane Whitlock ${ }^{1}$, Fonbeyin Henry Abanda ${ }^{1, *} \mathbb{C}$, Marcelline Blanche Manjia ${ }^{2}$, Chrispin Pettang ${ }^{2}$ \\ and George Elambo Nkeng ${ }^{3}$ \\ 1 School of the Built Environment, Oxford Brookes University, Oxford OX3 0BP, UK; kane.whitlock@gmail.com \\ 2 Department of Civil Engineering, National Advanced School of Engineering, The University of Yaoundé I, \\ Yaoundé P.O. Box 8390, Cameroon; mbmanza@yahoo.fr (M.B.M.); cpettang@yahoo.fr (C.P.) \\ 3 École Nationale Supérieure des Travaux Publics, Rue Elig Efi, Yaoundé P.O. Box 510, Cameroon; \\ gnkeng@yahoo.com \\ * Correspondence: fabanda@brookes.ac.uk
}

Citation: Whitlock, K.; Abanda, F.H.; Manjia, M.B.; Pettang, C.; Nkeng, G.E. 4D BIM for Construction Logistics Management. CivilEng 2021, 2, 325-348. https://doi.org/10.3390/ civileng2020018

Academic Editor: Angelo Luongo

Received: 22 January 2021

Accepted: 8 April 2021

Published: 16 April 2021

Publisher's Note: MDPI stays neutral with regard to jurisdictional claims in published maps and institutional affiliations.

Copyright: (c) 2021 by the authors. Licensee MDPI, Basel, Switzerland. This article is an open access article distributed under the terms and conditions of the Creative Commons Attribution (CC BY) license (https:/ / creativecommons.org/licenses/by/ $4.0 /)$.

\begin{abstract}
This study presents an investigation into the extent to which emerging building information modelling (BIM) can be applied to construction logistics management (CLM). Given the specialist nature of the domains, the study employed an in-depth qualitative interview, whereby six experts were interrogated about their experiences of BIM for CLM. The study found the main applications of BIM on CLM to be the creation of three-dimensional (3D) site layout plans and four-dimensional (4D) coordination of site processes and common user plant, updating the 4D logistics plan as the project progressed and collaboration in BIM-based logistics coordination. Furthermore, there was a consensus amongst interviewees on improvement in site safety, comprehension of logistics information, efficiency on site, and effectiveness of layout planning as the main benefits. Lastly, the lack of training with implications on understanding was one of the main barriers to applying BIM to CLM. The findings from this study have the potential to stimulate the uptake of BIM by construction logistics practitioners. By so doing, the performance construction project delivery can be improved, and waste can be minimised or eliminated.
\end{abstract}

Keywords: BIM; 4D BIM; construction; logistics; management

\section{Introduction}

Building information modelling (BIM) represents one of the most exciting and disruptive developments within the global architecture, engineering, and construction (AEC) industry. BIM can be difficult to define, even by those involved in the development of its systems. However, the description of BIM as getting the correct information to the right people at the right time has been often repeated within the construction industry since its introduction [1,2]. The adoption of BIM-based working has been accompanied by numerous potential efficiencies and cost improvements being advertised, alongside latent reductions in construction waste, in industry publications and literature alike [3-6].

Construction logistics management (CLM) and BIM have often been defined in a very similar way ([7]). From a CLM perspective, many authors [8-12] have defined it as the right resources (tools, materials, and operatives) delivered to the right location at the right time. On the other hand, Munir et al. [13] characterised BIM in a similar way, as the right information delivered in the right format and at the right time in a BIM process, from tendering to asset operations. On the basis of these characterisations, it can be inferred that CLM and BIM are about timely delivery of resources-construction materials for the former and information for the latter. Essential aspects of CLM include ensuring time efficiency, the coordination of deliveries to the site, the layout of the site itself, and the distribution of material resources from point of delivery to work phase [8,14]. Many studies have revealed that the management of these factors as the project progresses has a positive effect on labour output, efficiency, and construction waste [9-12,15]. This has been bolstered 
with the advent of BIM, which has further enhanced the benefits of a proactive CLM approach, pushing construction logistics practices towards optimum efficacy $[16,17]$ when both are integrated. Yet, the degree to which integrated BIM-CLM is employed in practice in managing on-site construction activities remains unclear.

This study aims to investigate the use of BIM for CLM and understand the extent to which BIM systems are being applied to logistics management of large projects, with a focus on the city of London. Through this inquiry, a more detailed picture of how BIM is currently being adopted to support this discipline and the benefits being experienced by those managing the construction logistics processes is developed. Furthermore, this research aims to provide an understanding of the issues that accompany the adoption of BIM for construction logistics management and any barriers associated with increasing the application of BIM to CLM where beneficial. This has provided insight into the adjustments that must be made in order to fully capitalise on the potential improvements in efficiency and reduction in waste, which this technology can offer. To facilitate understanding, the remainder of this work is divided into five sections. A review of CLM and BIM is conducted in Section 2. In Section 3, the methods used in this investigation is presented. Section 4 focuses on the data analysis of the study. Building on the analysed data in Section 4, the discussion and recommendations are presented in Section 5 . The study concludes by way of a summary in Section 6.

\section{Literature Review}

\subsection{Logistics Management in Construction}

The productivity of the construction site workforce greatly depends on the necessary tools and materials being delivered promptly-an aspect enshrined in CLM. From a business angle, logistics is generally considered the movement, storage, and delivery of materials and equipment for the purpose of ensuring the right item is in the right place at the right time [8]. On the other hand, in the field of transport, "logistics" is defined by the Chartered Institute of Logistics and Transport as the process of designing, managing, and improving supply chains, such as manufacturing, purchasing, storage, and, of course, transport [18]. Similarly, from the built environment angle, logistics management involves the strategic storage, handling, transportation, and distribution of resources, as well as the planning of a building site's layout and the active management and evolution of the site layout as construction processes unfold [14]. Akinci et al. [19] and Guerlain et al. [20] argued that enough space for big trucks to perform manoeuvres and unloading operations, and effective management of conflicts of space and time between resource movement and storage, are factors that can ensure easier accessibility and fluidity of sites to site workers, as well as plant and delivery operators. Furthermore, the coordination of the vehicle and material movement routes necessary must take into account the location, shape, and size of fixed and temporary facilities during each phase of the site for fluid construction sites without hindrances that negatively impact productivity [21]. Similar to most Western countries, the United Kingdom (UK) generated a total of 200 million tonnes of waste, with over half of this generated by the construction industry in 2012 [22]. Poor management of logistics is a major contributor to construction waste, and much of this comes about through poor material management $[23,24]$. Typically, $10-15 \%$ (and up to $45 \%$ ) of the total materials ordered for a project are either left unused or end up as waste by the end of the project [9]. This waste, however, is not only limited to the tangible debris disposed of during a project, but also extends to the labour and resources required to manage these wasted materials. In a study completed by Josephson and Saukkoriipi (as cited by Johansson [25]), operatives spent $10 \%$ of their time waiting on site for materials to arrive. The cost of this wasted time, plus the cost associated with the ordering, delivery, storage, and movement of these goods prior to their identification as redundant or damaged can, therefore, be substantial.

Through better management of the supplies delivered to site and a decrease in this waste material, a reduction in the overall waste generated by a construction project can be achieved. More efficient management of construction materials through better logistical 
practices presents an opportunity to improve industry productivity levels [26]. These improvements combined will enable the construction industry to shift closer towards the UK Government's targets for 2025. Traditionally, within the construction industry, logistics has not been a major focus, and each contractor taking part in a project was deemed responsible for their own individual supply chain, to provide the materials and resources defined by their scope of works [15]. This transfer of responsibility for logistics to trade contractors has conventionally been supplemented by the main contractor through the employment of agency staff to sufficiently resource remaining general on-site logistics requirements such as housekeeping, hoist operation, and management of site welfare facilities [14].

However, the employment of specialist contractors to take on the responsibility of logistics management is becoming increasingly common and considered a best practice approach to large construction developments [27]. The specialist logistics contractor (SLC) provides the benefit of a central point of contact for issues that affect the entire site, rather than specific trades only. Their role on the construction site means that much of their workforce is multiskilled, resulting in a team that presents a more effective means of controlling the tasks associated with material offloading and movement, waste management, and general site health and safety issues [14]. The improvements offered by a multiskilled logistics team mean that the use of an SLC can present substantial cost savings to clients despite the initial outlay. Trade contractors can typically spend around half their time unloading and moving materials, and the provision of a dedicated and qualified team of operatives to take on this responsibility results in trade time being more effectively spent. Combining this with the systemisation of material delivery management, the provision of a specialist logistics team can result in significant increases in trade contractor productivity [14,28].

As developments get larger and the complexity of supply chains becomes greater, logistics as an aspect of construction management has quickly become a key feature of preconstruction planning for complex schemes, as well as mainstream housing and fit-out developments [9]. The construction industry needs to manage its logistics creatively to meet demand safely and efficiently [29]. A number of methods available for managing the movement of materials to and around a construction site were covered in Whitlock et al. (2018) [30]; hence, they are not duplicated here.

\subsection{Building Information Modelling for Logistics Management}

With the assistance of BIM data, the burden of materials management on construction sites can be reduced, decreasing the risk of theft and damage, and streamlining site logistics [31]. Utilising contemporary laser scanning technology, existing buildings and areas surrounding a construction site can be accurately recorded and converted to a building information model, providing a contextual understanding for design and logistics planning [32]. BIM software supports the development of detailed three-dimensional (3D) plans for crane logistics, material staging areas, vehicular traffic/access, and material hoists [33]. Two emerging technologies that can aid in detailing 3D plans for logistics planning are Dynamo and 3D laser scanning. A fundamental process in space planning commences by defining the outcome and dividing the process into small steps-nodes (e.g., rooms and spaces, or components and assemblies) - which in turn are pieced together in a logical way to describe what it is the user wants to create [34]. This is analogous to the underpinning principle of Dynamo, where its definition or graph is the outcome, likened to sentence syntax in speech, creating a legible sequence and structure to define how data flows through nodes and their ports to achieve a desired result, be it writing to a known parameter or creating a new shared or project level en masse [34]. A study by Gebru and Staub-French [35] revealed how Dynamo can be used in space planning — an aspect of logistic planning. The beauty of Dynamo for logistics site management lies in the fact that, once site logistics are modelled in Revit, custom Dynamo graphs can help gain visibility into the model data, which is not possible with conventional non-BIM methods. Typically, a virtual design and construction (VDC) coordinator would have to generate a PDF or export a schedule from 
Revit to help the non-VDC team members review model data; however, any time data are disconnected from the model, there is a risk of referencing outdated information [36]. With regard to 3D laser scanning, Moon et al. [37] conducted a study about how point-cloud data from 3D laser scanners can be used in planning automated equipment operation planning on civil engineering work sites_an aspect of logistics planning.

Four-dimensional (4D) BIM allows proposed construction logistics plans to be contextually examined against three-dimensional site layouts and construction work schedules. This enables simulations of when and where site activities will take place within a 3D virtual environment. Through 4D BIM, logistics planning allows potential conflicts and inefficiencies to be easily identified at the outset of the construction process [21]. Linking the 3D model with construction activities through a 4D model (See example Figure 1) allows the site layout to be dynamically planned and site space to be suitably coordinated and allocated [38].

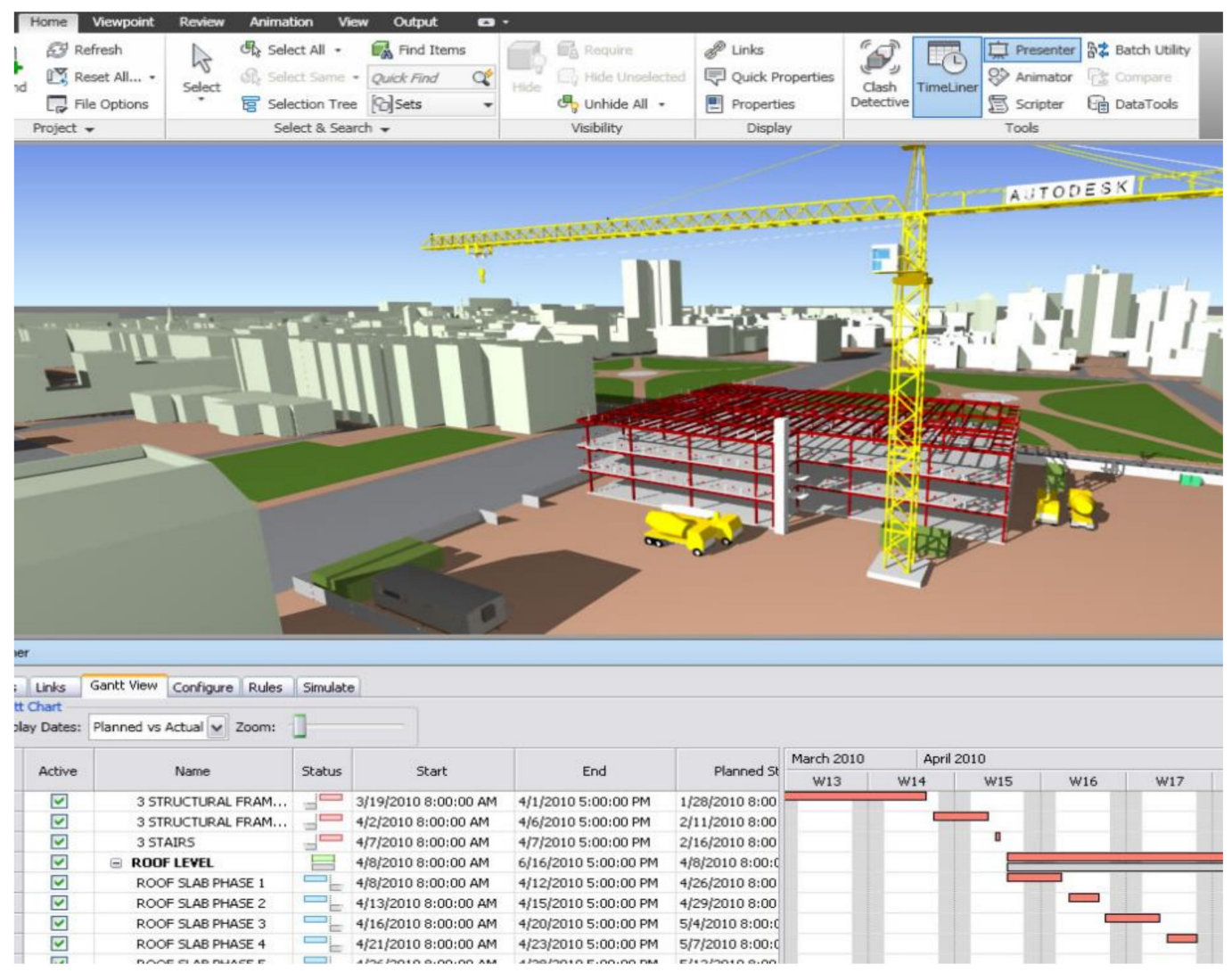

Figure 1. Example of Navisworks four-dimensional (4D) building information modelling (BIM) schedule incorporating logistical elements [39].

This data-rich virtual environment can allow the development of site layout plans to be automated, reducing the requirement for site layouts to be manually coordinated and updated [40]. The visual simulation offered by 4D BIM facilitates a contextual understanding of the proposed construction methodology, allowing non-professionals a clear understanding of site processes and, in turn, improving site safety [21,38].

BIM technology can enable logistics coordinators to manage demand smoothing with more control and precision. The production of construction drawings during the design process can no longer be considered a series of repetitive isolated tasks. The data-rich models produced through BIM-based design can lead to a more comprehensive analysis of the proposed structure; consequently, optimal solutions can be iteratively identified [41,42]. Combined with 4D BIM, a connection can be established among accurate material quantity data, the defined time by which each delivery is required for incorporation into the general 
structure, and the exact location the materials will be required. This presents a powerful tool for smoothing construction activity demands and improving the efficiency of delivery management systems $[43,44]$. BIM scheduling software also has extensive applications to the construction consolidation centres (CCCs) and supply chain management for material logistics administration. The integration of supply chain management techniques with the $4 \mathrm{D}$ model data enables the supply chain process to be visualised and the flow of materials to be monitored $[43,45]$. A consistently updated $4 \mathrm{D}$ building information model can enable a logistics coordinator to identify the exact quantities of each material required (or already installed) on the project at each stage. Depending on the level and quality of data available, this would facilitate the production of scheduled inventories for specific points in time, whether daily, weekly, or monthly. Through this process, the deliveries both to and from a project's CCC can be streamlined for optimum efficiency and accurate management. Rebolj et al. [45] pointed out that the tracking of material flow to and within construction sites is insufficiently supported by information and communication technology (ICT) tools.

In spite of this, Azhar [46] argued for BIM as a tool with a great potential for easy extraction of quantities and shared properties of materials from buildings. Such abilities have been well exhibited by 4D (time) and 5D BIM software systems [47,48]. Yet, the current literature scarcely mentions the use of BIM software for quantity take-offs from BIM models in a time-linked format for delivery consolidation, despite its ability to do so. The potential is even greater in offsite manufactured buildings where standardised components/quantities are easily linked to time [49]. BIM is considered to be critical to the successful implementation of an offsite manufacturing scheme [50], and its design software packages have extensive applications to offsite manufactured buildings [51]. Current technology enables a close coordination between different construction disciplines, allowing the prefabrication of building models that incorporate and integrate multiple building systems [52]. This, in turn, moves the design and construction process further towards manufacturing and, consequently, reduces the waste associated with poor material logistics [53]. By extension, just-in-time (JIT) delivery can also be improved, and the method can be extended to just-in-time production using BIM design software [12,54]. Engineered-to-order components can be produced later in the programme, reducing the waste associated with multiple handling, damaged and lost parts, and goods storage. BIM design software improves the ability of designers and fabricators to produce detailed shop drawings at short notice, allowing swift adaption in the event of design changes and decreasing the costs associated with late revisions [52].

What emerges from the preceding review is that much of the research surrounding the application of BIM to CLM was predominantly focused on the development of $4 \mathrm{D}$ BIM site layout coordination and the reduction in delivery requirements through design, such as off-site manufacture. It is clear that BIM potentiates many advantages in CLM and has a large number of applications to the coordination and management of the various disparate site processes that traditionally keep a site operational. However, the extent to which these various applications of BIM to CLM are actually being employed on current construction sites is unclear. There are a number of CLM tools that can be improved or facilitated by BIM systems. For instance, the research did not find any examples of "on-site marketplaces" actually in use, despite their recommendation by waste reduction organisations. It is possible that these can be more easily established through the extraction of detailed inventories from a well-developed BIM model, as identified by Azhar [46]. As Irizarry et al. [43] pointed out, current delivery management systems can also be made more efficient. The acceptance or rejection of deliveries is reliant on the knowledge of the project management individual(s) overseeing that element of the process; therefore, it is potentially exposed to human error and lapses in judgement. It is possible that these issues can be better managed through linking the delivery management system (DMS) tool to a 4D BIM, where combined spatial and temporal data are already incorporated within the model, and the policing of inefficient delivery practices can be simplified. A number of improvements in efficiency and reductions in material handling can be made through 
interconnecting these systems. Studies about such interconnecting systems between BIM and DMS are scarce [55].

Furthermore, BIM-based working procedures and guidance documents actively encourage collaborative working practices. Collaboration among a construction project's participants is essential for its effective delivery (BS 1192:2007 [3]). Yet, despite the high number of stakeholders involved in the coordination of common user plant (cranes, hoists, etc.), the delivery and storage management of materials and the focus on collaboration in CLM are seemingly lacking within both research papers on the topic and relevant codes of practice.

\section{Research Methods}

A combination of qualitative and quantitative methods was used to conduct this study. Firstly, given the exploratory nature of the study, qualitative research in the form of semi-structured interviews with individuals involved in 4D planning and BIM-based logistics management processes on projects in London was used. Since the interviews were recorded before transcribing and since this study is part of MSc research, the data collection approach was approved by the research ethics committee of Oxford Brookes University. Furthermore, participants were explained the purpose of the research and sent a consent form, which all of them completed and returned to the researcher before interviews were conducted, in compliance with Oxford Brookes research ethics requirements.

The research focused on specialists in the field of construction logistics that are simultaneously involved in BIM-compliant projects in Greater London. The choice of Greater London as a location focuses the study on one of the most pertinent locations of the UK construction industry with respect to CLM policy. London is one of the most highly populated and most congested cities in the world [56], a challenge that is further compounded by its challenging street layout [57], which leads much of the UK construction in policy changes to improve logistics efficiency; most of the construction logistics plan guidance documents available at the time of writing are published either by Transport for London or borough councils located in the city $[58,59]$. Therefore, by focusing the study on this specific location, it can be presumed that the study focuses on one of the most forward-thinking areas of UK construction logistics management.

Furthermore, the intent of this study is foundational in nature. BIM is relatively new to the construction industry, and, although many of its applications to CLM were identified to some extent within the literature review, it is unclear how many of these applications are being employed on current and active BIM-compliant construction sites in the UK. Considering the relatively new introduction of BIM to formerly established construction processes, there is a possibility that there are further applications to CLM that have not yet been identified or fully developed, thus appearing in the current literature to a limited extent only. The qualitative research method provides a detailed snapshot of the current synergy between BIM and CLM on active projects in an area that can be considered at the forefront of construction logistics.

Secondly, to further investigate the extent of the application of BIM in CLM, a structured quantitative questionnaire method was used. While the qualitative method was used for all research objectives, the qualitative method focused on BIM applications in logistics management, issues experienced using BIM for logistics management, and improvements experienced using BIM processes for CLM. These three parameters are quite important for BIM applied to CLM; as such, the quantitative technique was used to corroborate findings from the qualitative method.

\subsection{Research Design}

Semi-structured interviews with eligible individuals were based on a format that revolved around five primary questions. For each question, a number of potential followup questions were prepared in order to ensure that all relevant topics were covered by the interviewer during the discussion with each interviewee. First, the primary question 
was posed, and the interviewee was free to take their response in any direction. This permitted the respondent to cover the issues they considered most important. Following their response, where particular topics were not covered in their initial answer, the followup questions were posed for the purpose of ensuring no issues were overlooked. Follow-up questions were prepared as cues for the interviewer and, depending on previous responses, were not always posed verbatim. Keywords in each follow-up question were prepared in bold text in order to be seen at a glance, thereby ensuring that the conversational flow of the interview was not stifled. Furthermore, where topics were covered in initial responses, the relevant follow-up question was duly omitted to avoid repetition and ensure that the flow of the discussion remained consistent throughout the interview.

\subsection{Interview Recording and Transcription}

Where interviews were conducted in person, a recording was taken using a portable Dictaphone (Olympus Model VN-541PC) and transferred to a computer following the interview. The Olympus Model VN-541PC manufactured by Olympus was bought from a shop in London in the United Kingdom. In the case of one interview held via telephone, the call was made via Skype desktop software and recorded using a third-party callrecording application ('MP3 Skype Recorder'). The MP3 Skype Recorder was bought from DOMIT Ltd. London in the United Kingdom. An "intelligent verbatim" approach was utilised for transcription, whereby false starts, stutters, and filler words/sounds were omitted. Full sentences were formed retaining the content and context of the interview. In some instances, sentences/questions were left incomplete, due to either the interviewer or the respondent predicting the rest of the sentence and beginning to respond. These half-sentences were retained to provide context, and an ellipsis (... ) was added.

Prior to interviews, a number of large construction projects in central London were identified. Inquiries were made in order to source the contact details of individuals involved in either the preconstruction planning or logistics management process of those sites. The aim of this exercise was to gain as broad a range of perspectives in this area of the industry as possible; therefore, efforts were made to ensure each of the interviewees came from different, but related, backgrounds in the industry. These included individuals representing specialist logistics contractors, 4D BIM consultants, and site-based main contractor staff in project management, logistics management, and planning positions, as well as those overseeing overall main contractor BIM adoption. Due to the Greater London focus, there was some crossover among the respondents with regard to the developments they were involved in. Over the course of the selection process, 18 individuals were approached by email, telephone, or LinkedIn message. An interview expected to last 20-30 min was requested regarding their experience using BIM for CLM. Six individuals (A, B, C, D, E, and $\mathrm{F}$ ) responded positively and participated in the interview.

\section{Data Analysis}

\subsection{Involvement of Respondents in 4D BIM and CLM}

Table 1 offers details of the number of projects that each respondent was involved in that used BIM for CLM, as well as the types of development featured in these projects. 
Table 1. Details of the number and type of projects each respondent was involved in that used BIM for construction logistics management (CLM).

\begin{tabular}{|c|c|c|c|}
\hline Respondent Reference & $\begin{array}{l}\text { Number of Projects } \\
\text { (Using BIM) }\end{array}$ & Comments & Types of Projects \\
\hline $\mathrm{A}$ & $1+$ & $\begin{array}{l}\text { Only } 1 \text { memorable instance where } \\
\text { Respondent A was issued with } 4 \mathrm{D} \\
\text { information; however, Respondent A } \\
\text { was involved in a number of projects } \\
\text { that had a 4D logistics model } \\
\text { prepared (and not issued/shared). }\end{array}$ & $\begin{array}{l}\text { Enabling project (for a future } \\
\text { residential development). }\end{array}$ \\
\hline B & 2 & $\begin{array}{l}\text { Low number likely due to being } \\
\text { resident on long-term developments. }\end{array}$ & $\begin{array}{l}\text { Large commercial and } \\
\text { residential developments. }\end{array}$ \\
\hline $\mathrm{C}$ & Expected 100+ & $\begin{array}{c}\text { No exact number given; however, } \\
\text { Respondent } C \text { oversees all United } \\
\text { Kingdom (UK) projects for a major } \\
\text { contractor. } 100+\text { is no doubt a low } \\
\text { estimate. }\end{array}$ & $\begin{array}{l}\text { General developments } \\
\text { predominantly include } \\
\text { hospitals and rail projects. All } \\
\text { projects conducted by } \\
\text { operating unit involved piling } \\
\text { and ground engineering. }\end{array}$ \\
\hline $\mathrm{D}$ & $400+$ & $\begin{array}{l}\text { High number due to being } \\
\text { responsible for preparing } 4 \mathrm{D} \text { logistics } \\
\text { plans for a number of global clients. }\end{array}$ & $\begin{array}{c}\text { Large residential and } \\
\text { commercial projects, major } \\
\text { infrastructure developments } \\
\text { including rail, highways, } \\
\text { hospitals, and schools, and } \\
\text { stadia, nuclear plants, and } \\
\text { military installations in active } \\
\text { warzones. }\end{array}$ \\
\hline $\mathrm{E}$ & 3 & $\begin{array}{l}\text { Low number likely due to being } \\
\text { resident on long-term developments. }\end{array}$ & $\begin{array}{l}\text { Schools and (the current) } \\
\text { high-rise commercial project. }\end{array}$ \\
\hline $\mathrm{F}$ & $1+$ & $\begin{array}{l}\text { Low number due to being resident on } \\
\text { long-term developments. Respondent } \\
\text { F has only been involved in logistics } \\
\text { management (and to a limited extent) } \\
\text { on the current project. }\end{array}$ & $\begin{array}{l}\text { Large mixed-use commercial } \\
\text { and residential development } \\
\text { in Central London. }\end{array}$ \\
\hline
\end{tabular}

There is a high degree of variation in Table 1 ; however, this is almost certainly reflective of each individual's differing role and position in the industry. For instance, Respondents $\mathrm{B}, \mathrm{E}$, and $\mathrm{F}$ are in roles where they would be retained by the main contractor on a single project from its commencement until its completion; conversely, Respondent $C$ oversees all UK projects for a main contractor and, therefore, the number is considerably higher.

Similarly, Respondent D is involved in the production and supply of 4D site plans to main contractors and developer clients. The preparation of these is a primary service that his company provides; therefore, it is not a surprise for Respondent $\mathrm{D}$ to have been involved in a very high number of such projects. The high frequency of $4 \mathrm{D}$ site plan creation by this firm (approximately one project per week) is, however, a positive reflection of the industry. It is encouraging that such a large number of major projects are utilising $4 \mathrm{D}$ BIM to coordinate common user plant and temporary site processes.

The quantitative questionnaire was dispatched to 170 professionals working in the construction industry. Of these, 69 responded, representing a response rate of $40.6 \%$. This is significant, given that a response rate between $25 \%$ and $35 \%$ is considered acceptable in the construction industry [60]. The experience of the respondents is presented in Figure 2. 


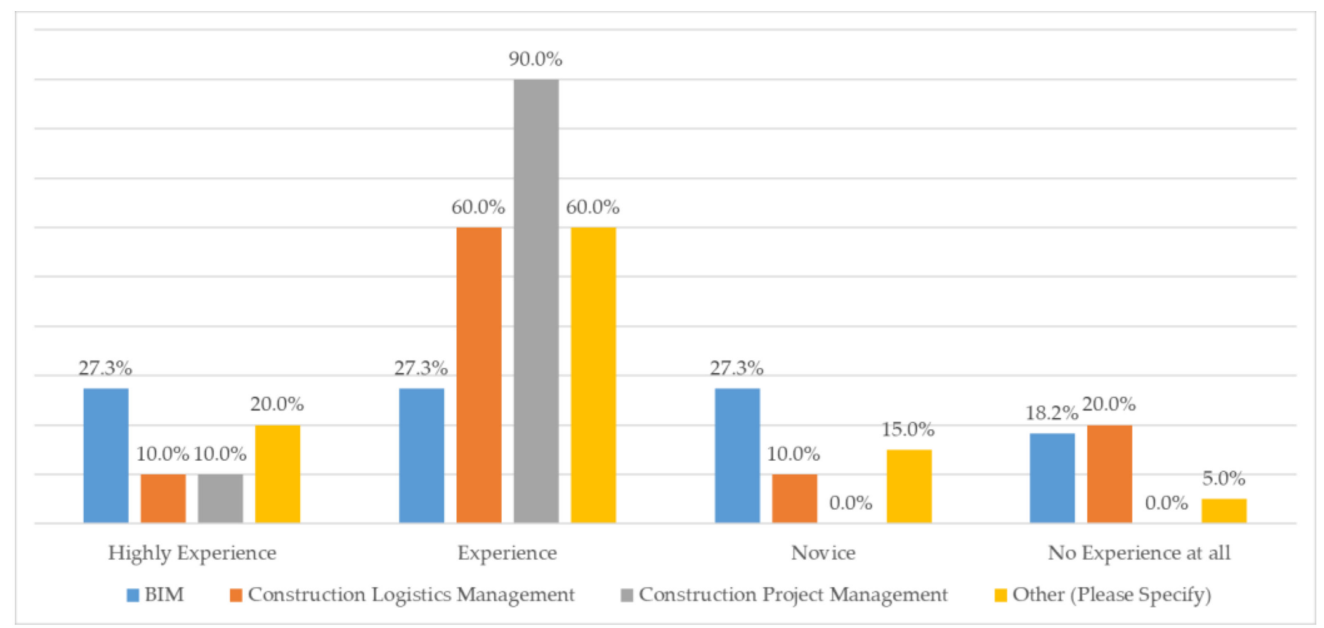

Figure 2. Level of experience of interviewees.

According to Figure 2, the respondents had more experience in construction, followed by CLM and then BIM. This is not surprising as BIM is still emerging and still facing resistance to adoption.

\subsection{To What Extent Has BIM Been Used for Logistics on the Projects Respondents Have Been Involved in}

Respondents were queried on the extent to which BIM software and systems were applied to the logistics process on construction projects they were involved in, and their response informed the subsequent questions in each interview.

4.2.1. Creation of Three-Dimensional Site Layout Plans and 4D Coordination of Site Processes and Common User Plant

Respondents were asked whether the projects they were involved in had 3D site layout plans prepared, and whether these were used for $4 \mathrm{D}$ coordination of logistics processes such as the installation, movement, and removal of common user plant and installation of hoarding.

All respondents indicated that at least one of the projects they were involved in included both the development of three-dimensional site layouts and the preparation of four-dimensional logistics coordination plans, to varying degrees of detail, as part of the preconstruction process.

Among those interviewed, there were no instances of 3D site layouts being produced without time-based data being added for $4 \mathrm{D}$ site coordination. However, depending on each respondent's relative position within the industry, their access to and involvement with such information varied.

In each instance, the 4D BIM model was predominantly used to visualise and coordinate the installation and removal of common user plant such as tower cranes and hoists. In some interviews, further uses were specifically referenced, such as visualising the installation and movement of site boundary hoardings (Respondent A), delivery and installation of large permanent plant items such as hospital equipment (Respondent C), and delivery and distribution of general materials (Respondent B). Respondent $\mathrm{C}$ also detailed the use of Synchro 4D BIM software to coordinate the delivery of materials via train on rail projects.

Furthermore, in reference to the above applications, Respondent $\mathrm{D}$ asserted the need for these 3D logistics objects to be modelled to a high degree of accuracy:

The area that you're looking at is plant, temporary works, and logistics. The interface with them, dynamically, in time, with the permanent works is what you're looking for. So, therefore, the accuracy of those plant, temporary works, and logistics has got to be there... That's critical. Absolutely critical. 
It was explained, by Respondent $\mathrm{D}$, that good 4D logistics planning was reliant on these three-dimensional objects being an accurate representation of the real object being used on the site, and that effective time/space clash detection could only be achieved by plotting everything out in detail and modelling everything to the millimetre.

Conversely, Respondent F maintained that preparing much of the construction logistics information in 2D was necessary to ensure clarity and properly communicate the finer details of the logistics methodology:

... the finer details you'll get in the $2 D$, where everything is more descriptive. You need to tell the clients "Okay I need this site boundary to be this big" and how you give that to the client is with a 2D drawing. You don't give it to them with a 3D model.

\subsubsection{Updating the $4 \mathrm{D}$ Logistics Plan as the Project Progressed}

Following a positive response regarding the development of 4D logistics plans, respondents were asked whether these were kept up to date with any amendments to the programme and changes to site layout and conditions. The purpose of this was to discover whether, on occasions where unforeseen circumstances caused changes to the initial plan, those with access to the $4 \mathrm{D}$ model returned and edited it to reflect the new circumstances. In only one instance was this the case. Respondent $B$ described a situation where the $4 \mathrm{D}$ BIM model became a point of reference for the project team and was constantly revised and streamlined depending on the situation out on site, with feedback from trade contractors:

... that's constantly being updated ... [the planner has] gone away and is remodelling that as we speak, just to make sure "does the sequence work?" and then feeding that back into the programme, rather than the other way around: doing the programme first and feeding into BIM. We're working it on the model to go back into a traditional programme.

Respondent B claimed that the application of the $4 \mathrm{D}$ model as a point of reference for logistics coordination led to drastic improvements in delivery efficiency. Respondent $B$ described the experience of continually returning to and reworking the model in order to maximise the volume of deliveries they could get in and out of the site gates. The original capacity of one delivery per half-hour slot was increased to between four and five deliveries in the same period, through the application of 4D BIM-based delivery coordination.

This, however, did not appear to be a typical procedure. For others that were developing or working with $4 \mathrm{D}$ logistics plans, it seemed to be an uncommon practice to return to the 4D BIM model. Respondent F argued that the absence of this practice on their site was due to the excessive resources required for effective execution:

Let's say you have a team and you have a $4 D$ resource, a $4 D$ person, allocated to just doing logistics, that would be great. That person would be doing logistics every day, Synchro models and visualisations, and that is something you could do on a couple of weeks or couple of days basis, or weekly basis—but ... there's heavy resource needed in my opinion. You need a lot of input; you need a lot of time to get these things right. It's very time-consuming.

Respondent $\mathrm{D}$ described a situation of developing the baseline $4 \mathrm{D}$ models and handing them over to their main contractor client; however, the question of whether these were adapted by the main contractor following that initial hand-over was described as a "hot topic". It was mentioned that these models were set up for the main contractor to have flexibility and efficiency to adapt to change as it occurs:

A lot of the time it gets handed over and fair enough they use it to iron out all the issues pre-start and when they've just started, so it is valuable. But, once it's there, and given the process, it should really be kept up to date. There's not a lot involved in doing that.

Respondent $\mathrm{D}$ further reiterated that keeping the model up to date was an area where the use of BIM could be improved or increased in its application to logistics management later in the interview. 
Respondent C, from the point of view of overseeing BIM adoption for a large number of projects on behalf of the main contractor, described a situation where the $4 \mathrm{D}$ logistics plan was not being updated following its initial preparation:

What I tend to see is: "This is how we're going to perform the logistics" and then whether it's kept up to date ... I'd love to say "Of course it is", but I haven't seen that.

Given the benefits described by Respondent B, it is discouraging that the process of returning to the $4 \mathrm{D}$ BIM model, to revise the logistics plan for present and future site coordination, is so rarely applied.

\subsubsection{Collaboration in BIM-Based Logistics Coordination}

Respondents were questioned on their experience in collaborative methods of working with regard to BIM and CLM, notably in reference to trade contractor involvement in 4D logistics management processes and sharing of 3D models and associated information, both prior to and during construction works.

With the high number of projects utilising BIM for CLM identified in Table 1 above, it might be expected that the managing director of an SLC such as Respondent A would have overseen a high number of projects that utilised BIM-based systems for logistics management and coordination; however, this was not the case.

Respondent A indicated that there was only one memorable (and recent) instance where he received three-dimensional logistics information.

Respondent A explained:

Jobs where we've actually had it in the beginning are absolutely minimal. We are slowly seeing it creep into tender documentation. We had a recent project where the document included a fly-through model (animation)... But, to be honest, there would be a handful of times where I've seen that before ... the majority of projects where we get the logistics plans, relating to programme as well, are all just $2 D$.

This was a surprising result given that this contractor was employed on a number of developments that were listed on the website of Respondent D's BIM consultancy as projects where $4 \mathrm{D}$ logistics plans were completed.

During the interview with Respondent F, it was explained that, although large static plant items, such as cranes and hoists, were incorporated within 4D BIM to illustrate their proposed methodology to the client, more detailed logistics information remained in 2D format to ensure clarity:

At the beginning of the project, we did the Synchro model, but it was a visual on how everything gets built. And that's great because you give it to the client and you tell them "Okay, this is how we're going to build it" ... in the 3D model that we present to the client, we'll have the tower cranes going up, when the tower cranes go ...

... but the logistics is purely only 2D. So, it's not being done in $3 D$... the finer details you'll get in the $2 D$, where everything is more descriptive...

When probed on why 4D BIM information was rarely issued to the SLC, Respondent A reinforced this suggestion:

[4D information is] certainly something that would add value to all our projects, but the best way of adding value is disseminating it to all the trades, so they get to have a look at it and it's not just kept in isolation ... maybe they're just using it for visuals or as a marketing thing with clients...

As a representative of a main contractor, this explanation was mirrored by Respondent B:

... you could almost say it's like a marketing tool. It gives you a good overview of the job, it doesn't give you so much the detail ... We've done sort of six-minute videos, so it gives everyone a broad idea of what we're actually trying to achieve out on site ... we would've done all the $3 D$ and the $4 D$ models, and we've done all the fly-throughs but then we just make it a $2 D$ paper exercise for the sake of tendering ... so that's probably 
what everybody gets. When they come in for the tender interviews, we might show them on the screen ... but it does tend to be part of the package that it's more 2D drawings.

The above approach does not seem to be a constructive method of collaborative working. Open access to information is a foundational element of best practice BIM protocol, yet it appears that the 4D model is rarely directly shared with those that may be pivotal in ensuring its feasibility.

Collaboration among the various parties involved in a construction project is a fundamental principle of BIM systems. Respondents were asked whether there was any collaboration between trades and main contractor in the application of 4D BIM to CLM.

In all but one instance, respondents described at least one occurrence of collaborative involvement where trades were invited by the main contractor to view the 4D BIM model. It was reported that this was for the purpose of improving the efficiency of proposed logistics plans, identifying elements of the 4D model that conflicted with their work, and providing a clear overview of the planned sequence.

Respondent D:

We want to work with the trades! We want full visibility, transparency with the team. We want everyone to look at it. We want the team to feed their ideas back into the logistics or the programme, and that's how I think it should be done.

Respondent F explained that, on their own project, they utilised the suppliers' input during the earlier planning stages:

... you invite all your different suppliers, because, before you start on site, you need a very good idea of how you're going to build the thing so, yes they did have an input... you know where the hoist is going to go, and the tower cranes are going to go, but to a limited amount of information. You probably know, like $80 \%$ sure, everything, but things change.

Respondent E described the experience of inviting the proposed crane operators to access the 3D model within a virtual reality environment: to make sure that the driver can see what he's doing, where the banksman is going to be stood, where it is going to slew to.

Access to this same virtual reality environment was also extended to the resident cladding contractors so that they could gauge the expected site conditions when they arrived on site:

It was like going into a time machine almost; you could go forward in time and know exactly what the site was going to look like... so, the cladding guys, they did a bit of playing around with it ... They would have a model and they would go on their floor plate, walk around their floor plate, put their cranes out, their launching tables, and see where they're going to be.

However, this virtual reality-based collaborative involvement was part of an experimental system on a forward-thinking construction site. It should be recognised that this was an atypical application of collaborative working methods.

With the exclusion of the SLC (Respondent A), all individuals interviewed experienced situations where the trade contractors were invited to view the $4 \mathrm{D}$ model alongside their peers on site during the construction stage to offer professional input on potential issues and possible methodological improvements. It should be noted that, in some instances, it was not clear whether this was being applied to logistics management or simply an example of general coordination and interfacing between trades. However, Respondent B described a scenario that was specifically aimed at logistics coordination:

... so, now we're talking ... as to how best to use all the logistics routes and the canti-decks ... we are trying to minimise the amount of crane time, and also the amount of canti-decks by getting all three of them [the specialist trade contractors] together and all working through the model... 
It seemed the case that, generally, respondents believed that the frequency of these collaborative coordination sessions should be increased, and that their application to logistics should be improved.

Respondent D said:

Well it often is that way, what with it being new technology, and a different way of working; implementation among a full team is ... I'm not going to say rare ... but it's not uncommon for it to be not utilised to its maximum which would be getting it in front of the trades and anyone who's involved in the project, getting their eyes on it...

Respondent $B$ reiterated this:

... is that something that the main contractor should be leading? It was a perfect example this week... Everybody was in the room looking at the screen trying to work out the solution by looking at a model which is three months in the future-do we do that with everyone? No, we don't. And again, do we do it coordinated like that? Not very often. We'll still have our logistics meeting week by week, and that is on a $2 D$ drawing just in front of everyone.

Furthermore, four of the five individuals interviewed discussed the point of increasing the involvement from the SLC in the 4D logistics planning process, and they believed that the process of coordinating the site would be improved by doing so.

Respondent A, as a representative of a SLC, said:

I don't know if there was another [logistics] contractor involved ... [but] obviously the amount of gates, even hoisting, getting materials to the point of use, etc. and the labour involved - it certainly would help to get early contractor involvement.

Respondent B, as a project manager working on behalf of a main contractor, said:

I think we could probably work a little closer with our logistics team in terms of the sort of BIM or the 3D modelling. We tend to do it all in house, and then just tell our contractors or our logistics provider, instead of them driving us ... I think it's an industry problem that what tends to happen is the main contractor gets the job, does all the plans, and then you go to tender and try and get a logistics contractor. Rather than the other way around and trying to get a logistics contractor in first, and working alongside in some sort of partnership, or collaboration, before the job has even been tendered.

Respondent $C$, from the position of overseeing multiple projects utilising BIM systems, agreed:

We always say we should be working earlier with all of our sub-contractors, and, of course, when we actually get to the point, it's always a bit too late... The nature is "let's get someone to do the logistics for us and we can pass the risk down the line" and I think that if we work consistently with a logistics contractor, we can start to bring these things in. And we're trying to do that with our supply chain, we are narrowing down our preferred supply chain, we are prequalifying on their capabilities for BIM. But ... with the pre-qualification questionnaires (PQQ) and IT assessments ... there's a design bias.

According to Figure 3, it can be concluded that most BIM applications in logistics management create three-dimensional site layout plans. This is depicted in the bars, whereby $12.5 \%$ and $50 \%$ of the respondents said they "very often" and "often" used BIM for creating three-dimensional site layout plans, respectively. This corroborates views from in-depth interviews where all participants confirmed using BIM for creating threedimensional site layout plans. 


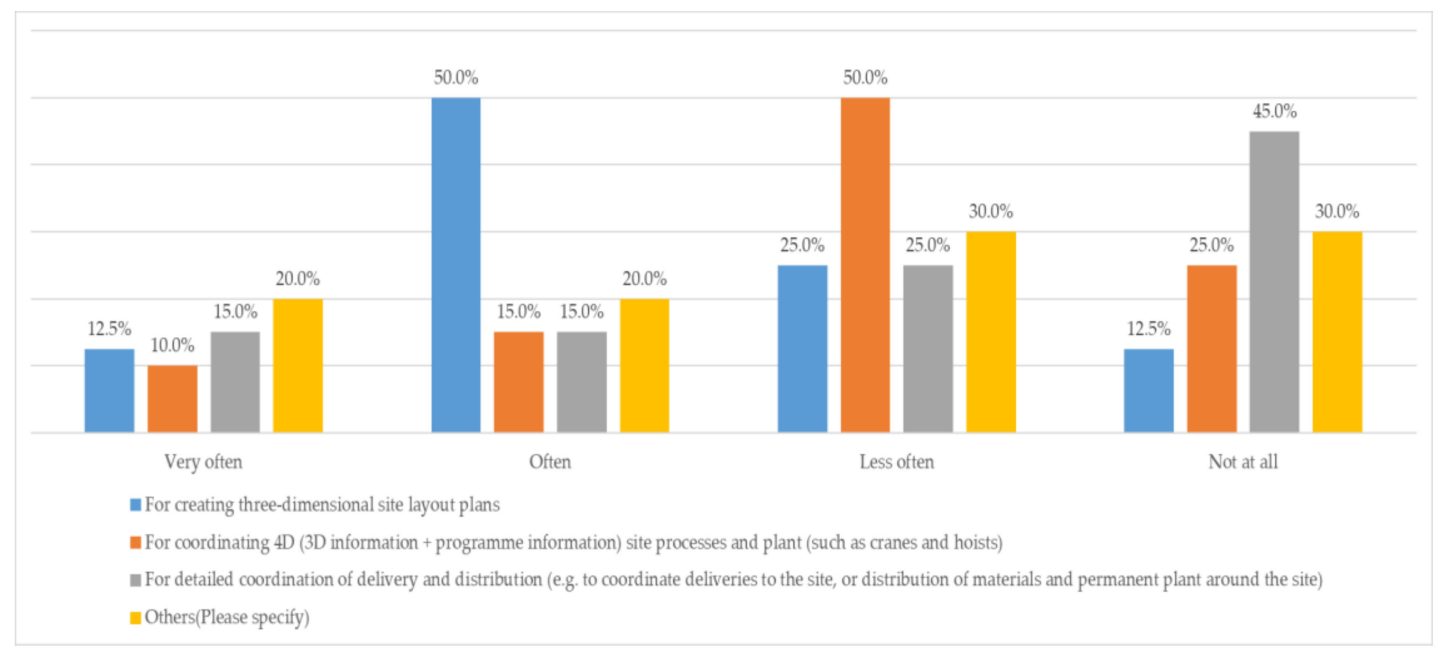

Figure 3. BIM used for logistics management.

4.3. Improvements Experienced Using BIM Processes for Construction Logistics Management

Respondents were queried as to whether they personally experienced improvements in four areas: Site safety, comprehension of logistics information, efficiency on site, and effectiveness of layout planning.

All respondents agreed that comprehension of logistics information was improved by the introduction of 4D BIM modelling. Respondent A described his experience:

Definitely, it was much, much easier. Particularly with the sequencing and temporary hoardings and changes to routes throughout the building ... It made it a lot easier to realise how intricate it was with the sequencing and separating these people that were in the building from the actual building works ... it undoubtedly makes things clearer.

With the exception of Respondent A, who unfortunately was not directly exposed to BIM-based CLM in practice outside of the tendering stage, all respondents agreed that site efficiency and effectiveness of logistics planning were also improved. The application of 3D site coordination tools averted potential major issues and increased the speed at which logistics planning could be completed through the ease with which potential clashes and problems were identified using the $4 \mathrm{D}$ modelling software. Respondent B said:

It's highlighted all the problems, and you can run the programmes again and again. It's easy to do it on a bar chart but it's much easier when you can see it on a 4D/3D model.

This sentiment was reinforced by Respondent E:

But you miss things: On a drawing you draw stuff and think "ah great, that works", but you go to do it in the real world when it comes to it and it doesn't quite work, and you have to adapt to it. That wastes time and money and resources... that was one of the things we found ... you looked on the drawing and it was there, but as soon as it was modelled, of what that moment in time was going to look like off of the 4D snapshot, you knew straight away [whether it was going to work] ...

Similarly, when asked if managing the logistics using BIM systems would improve safety on site, Respondent $\mathrm{F}$ noted:

Whatever you do on site, if you improve logistics, you're going to improve health and safety. That's because of the nature of construction.

All respondents who were involved in projects that utilised 4D BIM logistics planning were convinced that safety was improved by its application. However, it was identified how difficult it is to gauge any quantifiable improvement. Respondent $C$ noted: 
Well how do we measure that? Of course, I am going to say "Yes, we've improved safety" and "Yes, we've improved logistics", but if we're not measuring it, we can't put a figure on it.

Despite the lack of statistical data, it was apparent through discussions regarding the application of 4D BIM to CLM that all interviewees held that there were clear benefits to be had managing logistics in this way. However, this initial investigation would be considered anecdotal only. Quantitative research into measurable benefits would be required to support this result.

Figure 4 reveals that $40 \%$ (definitely agree) and 40\% (mostly agree) of respondents stated that BIM applied for logistics management improved safety. A similar result was obtained for the effectiveness of BIM for 3D layout planning. For the last two parameters, $40 \%$ (mostly agree) and 30\% (definitely agree) of respondents stated that BIM helped improve the comprehension of logistics information and efficiency of logistics processes. These results align with those from in-depth interviews and also confirm the benefits of BIM for construction site logistics management.

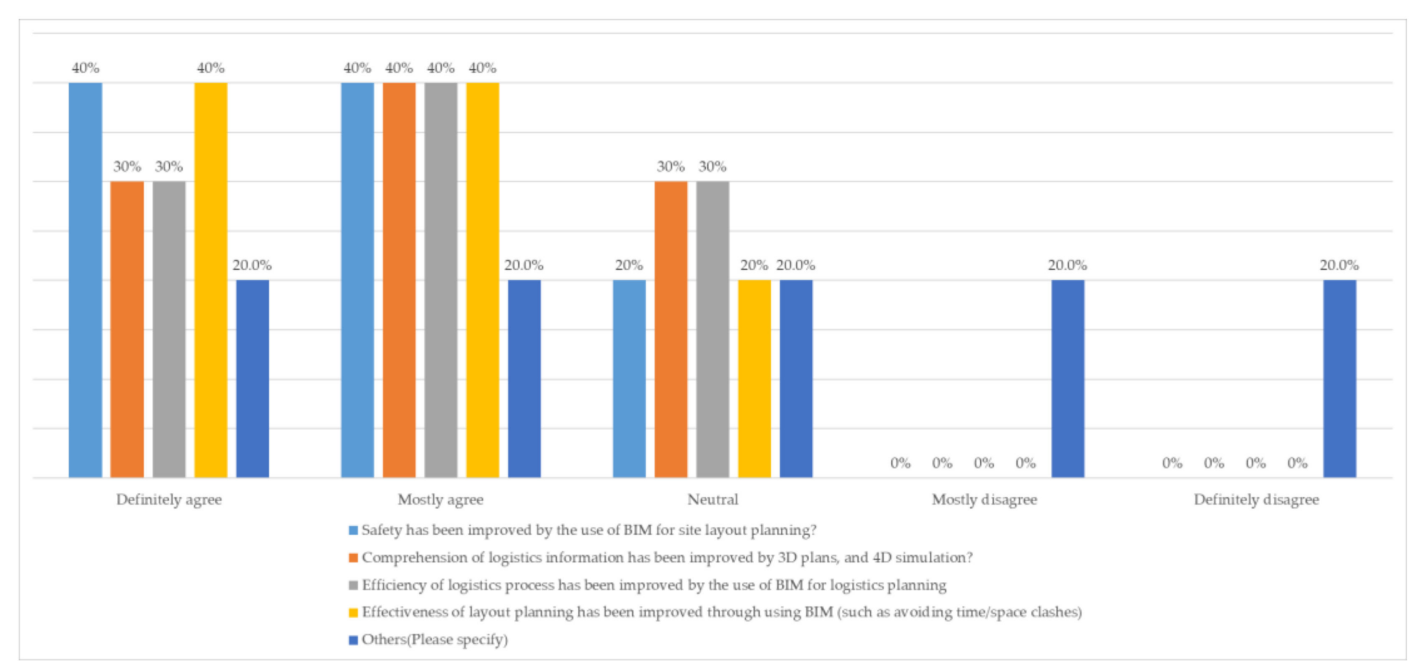

Figure 4. BIM improvement for construction logistics management.

\subsection{Issues Experienced Using BIM for Logistics Management}

Respondents were queried on the issues they felt were apparent when using BIM for logistics management. Considering that, where applied, interviewees had had a positive experience in the application of BIM to CLM, it was deemed necessary to identify any possible barriers to capability and wider adoption.

With the exception of Respondent $\mathrm{F}$, the individuals involved in the preparation and adaption of $4 \mathrm{D}$ Logistics Plans did not report any issues with the time required to prepare $4 \mathrm{D}$ logistics plans.

Respondent D explained:

... when it comes to $4 D$, it's the easiest one to adopt. Your planner is using planning software, you're not asking him to use anything else... Your model is already there, if it's a BIM project; the design team have modelled it ... Well they're the two main ingredients, the other one is the 3D model of the logistics ... there's not a massive amount of time in there to put a $4 \mathrm{D}$ model together.

However, Respondent F asserted that they did not have the resources available to continually update detailed logistics plans:

Because site is not ... a factory, where everything is static and you can say ... "the plan is this" and, maybe if something changed, it would be a minor change. On site, everything changes and something I've planned in the morning may be completely different by this 
afternoon or tomorrow morning. So, in order to keep up with the changes, it would be one resource as least dedicated just to doing that; just to change the synchro model and update the models and update the plans.

Respondent $C$ believed that quality of information was possibly an issue and explained that, although specified as "BIM Level 2" at tender stage, many of the models were often not up to the required standard to make the process as efficient as it could be. Furthermore, Respondent $C$ identified training as a primary issue, also:

I think the problems are more likely that we don't always quite get the models that we need, and the training issue. I think what often happens is that you get on a project someone called a BIM coordinator, and unfortunately what will happen is often that BIM coordinator will be the go-to person, "Oh can you do the 4D to help us do logistics?" ... and actually, what they should be doing is showing the planner, the logistics person, how to do it themselves.

Respondent B mirrored this, identifying lack of training as the major barrier to wider use amongst his team:

I always have to ask [planner], who's our man at $4 D$, to run the model, to do this, do that. I think it could be used a lot more with training. I've never been trained; I have no idea how to use Navisworks whatsoever; I don't have it on my PC, so I am still the dinosaur using $2 D$ and bits of paper...

Similarly, when queried on the issues experienced using BIM for CLM Respondent D explained:

I can't think of a single problem... The biggest issue for $4 D$ BIM is the adoption really. It's like any new thing. It's education, it's a lack of understanding of what it is... I think the issue is the implementation and getting people to use it.

The lack of training for staff and education to increase adoption was an issue repeatedly raised by respondents. Respondents A, E, and F all alluded to an ageing workforce and a possible age divide among staff when it came to utilising contemporary construction management tools such as $4 \mathrm{D}$ BIM software:

There are other people, older people, and they don't understand how the model works, or they don't see it. They'd rather have a piece of paper.

(Respondent F)

These individuals explained that this was a potential barrier to wider adoption as there are people that have just ignored it and have no interest in it, and they have no interest in using it (Respondent $\mathrm{E}$ ), and that people are quite set in their ways. They have always built that way and that's what they feel comfortable with (Respondent A).

As Respondent $\mathrm{D}$ pointed out, increasing education of staff in the applications and benefits would potentially improve this issue.

Figure 5 reveals $50 \%$ (mostly agree) and $10 \%$ (definitely agree) of respondents highlighted poor quality of information and lack of time in creating the relevant information as major issues experienced when using BIM for logistics management. Similarly, 20\% (definitely agree) and 30\% (mostly agree) of respondents stated that insufficient training and lack of motivation or encouragement strategies hindered the adoption of BIM for logistics management. These results corroborate the findings from the in-depth interviews. 


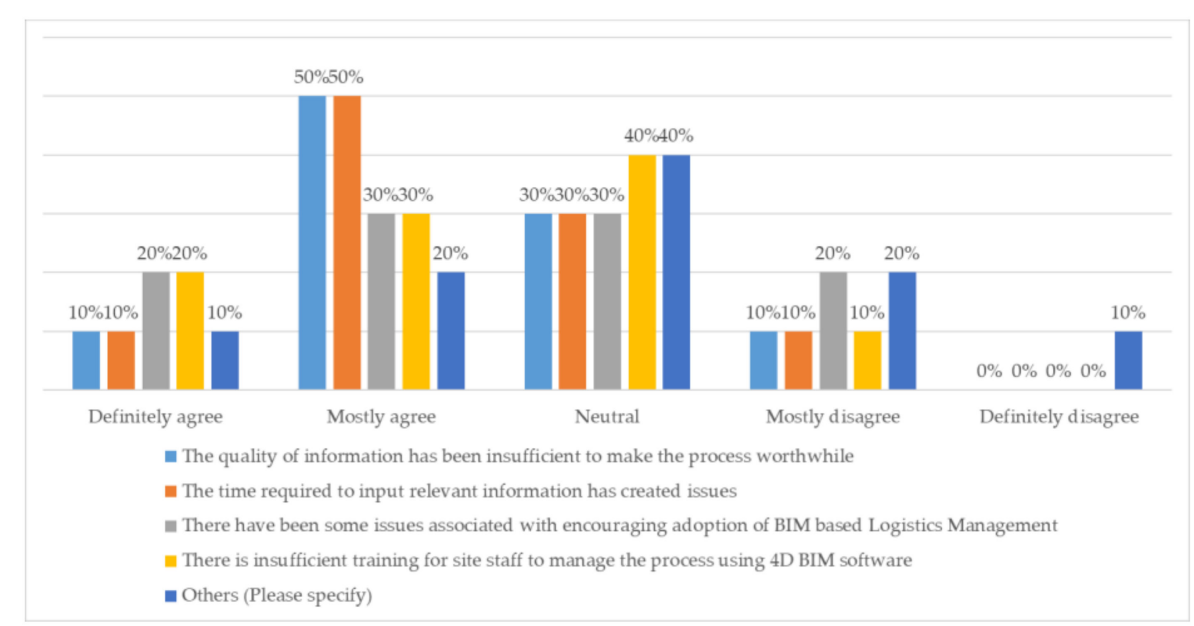

Figure 5. Experience using BIM for logistics management.

\subsection{Increasing and Improving the Use of BIM for Logistics Management}

Respondents were queried as to how the use of building information modelling systems could be increased or improved in their application to logistics management. Responses are detailed below.

\subsubsection{Advancing Collaborative Involvement from Trades}

There was a consistent sentiment that collaboration should be increased among the various parties involved in the coordination and management of disparate construction and logistics processes. With both Respondent $C$ and Respondent $D$, the possibility of federating the various $4 \mathrm{D}$ models prepared by separate trades and disciplines was discussed.

Respondent D explained how it might work:

... the interesting idea I had, and we've never done it, is to treat it like a proper federated model ... So, with Synchro, you can open up a blank [SP] file and you can import other Synchro files into that ... So ... you say "Right... [steelwork contractor], here's your programme, and your steelwork, we want you to send that as an 'SP' file" ... "Right, [concrete contractor], we want you to do the same with the concrete" ... and you bring all these into the Master model ... they keep it up to date, and they keep sending in their "SP" [files] and the main contractor has the overall one.

The only issue there is who does the logistics ... ? Who puts in the tower cranes, because they're shared aren't they? And who puts in the hoardings, and the hoists and access routes and welfare ... ? Maybe the main contractor does that little bit. I'm not sure, but I think it's something I have always thought about, but never explored.

Hypothetically, this process would improve the collaborative contribution from the trades on site as to how all elements of work are coordinated. The clash detection process that is currently applied to design conflicts on BIM Level 2 (now called BIM Stage 2) projects could also be applied to the construction and logistical processes. Respondents acknowledged that collaborative involvement from trade contractors was a productive process where applied; this alternative method would have the benefit of also allowing trades to remotely inspect and scrutinise the proposed construction sequence in greater detail. It is possible that delivery and material distribution proposals can be incorporated into each trade contractor's 4D model, allowing a third-party, such as the SLC, where employed, to coordinate the overall construction logistics management process.

Rather than being an opportunity to both identify and resolve issues, 4D BIM coordination sessions between main contractor and trades (as described by Respondent B) would be an opportunity to resolve complex time/space conflicts only. This would reduce the frequency of construction coordination meetings and simplify the overall logistics planning process. 
To streamline the current process in this way, however, early involvement from trade contractors would be of paramount importance. Both Respondent $C$ and D pointed out that the prompt appointment of trade contractors would be a primary factor in any such shift in procedure.

\subsubsection{Application of 4D BIM Systems to Material Distribution and Delivery Management}

The application of $4 \mathrm{D}$ BIM systems to DMS software was identified as a knowledge gap following the literature review, and this subject was raised during interviews.

Respondent $C$ noted that the management of deliveries was the point at which he believed there was currently a breakdown in the logistics process:

Where does logistics break down for us? It's actually trying to manage delivery tickets ... How do we manage delivery tickets and how do we stop the blockage at the gate? ...

That's where a lot of things breakdown I think and we're looking at how to solve that as a problem.

Respondent B described the situation at his current project, and it was acknowledged that there was no precise science supporting the decision to accept or reject a delivery. Generally, the package manager or construction manager overseeing the relevant work would manage the acceptance of deliveries on the basis of their own knowledge of the impending works and the space available for material storage. He suggested that, sometimes, to avoid multiple deliveries being booked in, purely for the purpose of JIT, the individual policing deliveries would accept multiple loads being delivered in one visit, which would then be stored on site ready for installation.

Respondent B explained:

... we would tend to just go with the feel of the job ... Knowing you've got space for materials you don't want to run out of ... equally, you don't want two hundred packs of blocks if there's nowhere to put the damn things...

You know what's coming up over the next few weeks. If you're suddenly going to flood the job, you then just know through knowledge rather than computer programmes. You could argue that both ways really: the computer says, over the next certain weeks, you're going to be building loads of walls for instance ... obviously you're going to need that space for materials to be hitting first.

This method of delivery management and administration of storage space is based on a manager's best judgement. This leaves the process potentially exposed to human error. It should be noted that Respondent $B$ did not report having experienced any issues managing deliveries in this way; however, it could be argued that the technology is available to avoid making this process reliant on experience and reasoning alone.

Respondents were asked whether they could see any benefit to incorporating 4D BIM information within delivery management systems. From the point of view of the SLC, there were a number of potential advantages to connecting the DMS with 4D BIM software; Respondent A described where efficiencies might be had:

Typically, on central London sites, we use a delivery management system so all the trades book in, so we know what's coming to site. If we could tie that into the BIM model, then we could be a massive facilitator for the main contractor... I mentioned before about materials coming onto projects too early, we'd be able to police that for the main contractor ... Knowing when materials are coming in, picking up defects, or if something is not the correct material ... these are all, logistically, things I think we as a company could develop into providing for the main contractor, and at the same time assist all the specialist trade contractors as well. Make their lives easier. They want their materials on site at the right time, in the right place, so that they can get them installed, and install them correctly without coming across damage because they've been on site too long.

Similarly, Respondent F pointed out the benefits he could see in such a system: 
To be able to interrogate the model ... if the model was online let's say, and I know something has to come tomorrow ... If there was a way that I could interrogate that model and say, "Okay, this piece of steel. When is it coming?", click on it, and it tells me delivery is scheduled for tomorrow morning, that is information I can use to feed into my programme...

It'd be very helpful. It's all about trying to solve problems earlier. The more data you have, the better at the end of the day.

Conversely, Respondent D identified the issues he believed were associated with utilising current 4D software for this purpose, and his opinion that the application of those programmes in this way was not compatible with their supposed benefits.

The problem being there, and I mentioned before number of deliveries and wagons and things like that, Synchro $4 D$ is a 3D programme. You're visualising the programme. The main contractor's programme or a trade contractor's programme. They can only show the level of detail of their tasks. They haven't got a task for every delivery. And the beauty of $4 D$ is the job will be built in line with the programme. That's why you visualise it. You've got a bar chart or all these lines that tell you that's the best way to build it. It's only when you do it in $4 D$ you go "oh, I didn't spot that missing link there. And, therefore, I've got a problem with the programme". And that's the fundamental part: that you're viewing the actual programme. There's no manual intervention in the sequence. And what you're getting into with the deliveries and stuff like that, I'm not saying it wouldn't be worthwhile sequencing it out, but it isn't the programme.

Despite the above statement from Respondent D, it could be argued that issues of space and time resulting from deliveries and material distribution are inherently associated with the programme. Moreover, the level of detail of any particular task can be increased. The Synchro software that Respondent D referenced does have the ability to sub-divide elements of work into composite parts [61].

There is likely little benefit to modelling and simulating each individual delivery associated with a development; however, increasing the level of detail of an existing 4D BIM model, to include information on when requisite materials will be received and where they will be stored prior to installation, would allow project and package managers greater control over the delivery, material distribution, and site storage process.

This tool could potentiate greater clarity over the JIT delivery process or theoretically facilitate the production of accurate inventories for CCC use.

Respondent B identified a further advantage to the unification of these disparate systems and described the experience of distributing heavy cladding panels within a new building ready for their installation, before realising that their weight may cause permanent damage to the structure. Respondent B suggested that BIM may alleviate these issues:

There's also space planning as well-when we're certainly loading out some of the buildings - I think BIM could be used for that. We're still quite old fashioned in the weight distribution of, you know, panels and blocks and everything like that. But could you do that through BIM to make sure "right, this is where the model is, you can't put all your heavy cladding panels, for instance, all in a great big lump".

Using the BIM model to control this element of material storage administration around the building is a fitting application, as the model will already include the structural performance data of the surrounding environment. This would allow the software to highlight areas where particularly heavy loads must not be stored, to avoid damage to the structure. This also presents a further function where visualising the material distribution process could provide some benefit.

\section{Discussion and Recommendations}

Through a combination of the literature review and exploratory semi-structured interviews, a more complete image of the status of BIM-based CLM on current construction 
sites was established. This includes the extent to which BIM systems and software are being utilised to aid the CLM process, the concerns associated with both current usage, and an investigation of how the application of BIM to CLM can be expanded beyond its current application. This section describes five primary recommendations informed by the research that may positively affect the effectiveness of construction logistics management as a discipline and could, consequently, benefit the overall efficiency of construction processes throughout the industry.

\subsection{Update and Reference the 4D BIM Model as the Project Progresses}

The interviews revealed that keeping the $4 \mathrm{D}$ model updated to reflect changes during the project was not typically a standard procedure. In the one instance where this became standard practice, the advantages were seemingly clear; the efficiency of the logistics process was improved, and the application of the software in this way substantially increased the delivery capacity of the project, as well as accelerated the general coordination process. This is corroborated by a recent study by Bortolini et al. [55], which further proved how 4D BIM can be used to significantly improved the performance of construction projects.

There is no obvious reason why these same advantages would not be experienced on other large or complex developments, if BIM software were to be applied in the same manner. This would be a change in procedure rather than a full overhaul of the construction management process. The $4 \mathrm{D}$ model could be designated, by those directing the project, as the central reference for site management staff with regard to time-related issues and works coordination. If this were the case, the $4 \mathrm{D}$ model would be updated by staff as a matter of course, and logistics management, being one factor of this process, would be streamlined. Those managing individual packages and elements of work would be furnished with the ability to increase the efficiency of works through this central point of reference in a truly collaborative manner.

\subsection{Increase 4D BIM Training for Project Management Staff}

Proficiency with 4D BIM software was identified as a major issue during interviews. For the use of a central $4 \mathrm{D}$ model to be worthwhile and the above recommendation to be possible, the management staff employing the system must be capable of operating the software and capitalising on its benefits. Interviews highlighted the lack of training of site-based staff in how to operate 4D BIM software as a major issue. This aligns with Marefat et al. [62], where many authors argued that the lack of training is a major barrier to BIM applications including 4D BIM. A trend of increasing reliance on a small number of individuals that were trained was identified by a number of respondents. In order to effectively put the available technology to good use, those that would benefit from its assistance must be competent. Considering the apparent benefits of applying 4D BIM software to the logistics management process, improvement in ability would likely have a measurable carry-over to general construction logistics efficiency. Without this proficiency, the evolution from Level 2 BIM to Level 3 BIM (now referred to as Stage 2 and Stage 3 according to ISO 19650 (parts 1 and 2)) in the UK may be delayed.

A strategy of regular site-based group training sessions may aid this progression. Allowing each site team to learn the software together would encourage a collaborative atmosphere while enabling individuals to seek support from each other following each training session. This would reduce the reliance on specific individuals, which could potentially come about from a policy of independent training sessions.

\subsection{Increase Collaboration with Trade Contractors}

The interviews identified apparent benefits in pursuing a policy of collaborative involvement with trade contractors in the logistics management and works coordination process. Where this was applied, it was reported that, utilising the 4D BIM model as a point of reference, clashes and conflicts that were not immediately perceptible to the main contractor or through 2D drawings alone were quickly highlighted. This is similar to 
findings reported in Vilventhan et al. [63] that 4D BIM is very effective in the identification and resolution of clashes in projects. Furthermore, these sessions allowed trade contractors an opportunity to aid in the process of identifying and agreeing solutions to these issues alongside the same fellow trade contractors that they were interfacing with on site. The sessions described did not entirely differ from the general coordination and lookahead meetings that are already a standard feature of the construction management process on many projects. With respondents drawing attention to the ease and speed at which issues could be identified utilising the 4D BIM model, it could be expected that the omission of the $4 \mathrm{D}$ BIM model from these existing meetings may result in potential problems being overlooked and their identification being delayed, a potential disadvantage for the stakeholders involved.

The solution to this, therefore, may be the use of a current and central 4D BIM model as a point of reference within the regular coordination meetings already held on site. The reported improvement in comprehension associated with utilising a 4D BIM model could substantially improve the efficiency of both general construction coordination and logistics management processes. The attendance of a representative from the SLC (if employed on the project) would allow a clear forecast of expected delivery volumes and potential logistical issues, enabling the SLC to accordingly increase or decrease logistics facilities such as plant provision, traffic management operatives, and common user plant operators, thus reducing the preliminary operational costs of the project.

It should be note that the above recommendation would be entirely reliant on the application of the two preceding recommendations.

\subsection{Invite Specialist Logistics Contractors to Be a Part of the Construction Logistics Planning Process}

During interviews, it was highlighted that, generally, the site layout and common user plant coordination process were initially formulated by either the main contractor or a consultant working on their behalf and subsequently managed by the main contractor without any direct input from an SLC. Respondents agreed that, where a SLC was to be employed, there were potential advantages to increasing SLC involvement in both the initial planning and the ongoing management of site logistics. Considering their expertise and experience, as well as the proprietary logistics management systems at their disposal, there could be considerable advantages to engaging with these specialists earlier in the process.

Inviting early participation would provide greater clarity of the rationale behind particular decisions made on the management of various logistical elements. This understanding would subsequently provide a foundation for greater SLC autonomy once site works commenced, reducing the time attributed by the main contractor staff to managing logistical issues.

\subsection{Offer 4D BIM Model Access to Trade Contractors and Specialist Logistics Contractors}

In line with the above recommendation, authorising access to the current 4D BIM model for both SLC and trade contractors from the early stages of the project would allow them an opportunity to examine the proposed 3D programme in depth.

The SLC would have a chance to scrutinise the proposed site layout and the arrangement of common user plant, potentiating opportunities to identify inefficiencies and conflicts in the proposed logistics plan. Trade contractors would be furnished with the prospect of warning relevant parties of potential impending logistical issues associated with their works prior to their realisation. Although this can be achieved through $2 \mathrm{D}$ information alone, the ability to examine a 4D BIM model makes this process more streamlined and makes the subtler conflicts easier to spot. Efficient site planning was reported as one of the best benefits of 4D BIM by Kumar and Cheng [40]. Furthermore, permitting SLC access to 4D BIM data would allow the development of proprietary BIM-based CLM tools that might otherwise not be possible. This might encourage innovation within the 
industry, allowing main contractors to further capitalise on the benefits of BIM without additional investment.

\section{Conclusions}

The completed study aimed to explore the extent to which BIM can be applied to CLM. Specifically, the study focused on the applications and benefits of BIM to CLM, as well as barriers hindering its adoption for the latter. To facilitate understanding, the main findings are summarised in alignment with the research objectives. Firstly, it emerged that the main BIM for CLM applications involved the creation of three-dimensional site layout plans and $4 \mathrm{D}$ coordination of site processes and common user plant, updating the $4 \mathrm{D}$ logistics plan as the project progressed with collaboration in BIM-based logistics coordination. Secondly, the overwhelming feedback from the interviewees suggested improvement in site safety, comprehension of logistics information, efficiency on site, and effectiveness of layout planning as the main benefits. Thirdly, a lack of training with implications for understanding was one of the main barriers to applying BIM on CLM. Although these findings were obtained from in-depth interviews, they were corroborated by those from quantitative structured questionnaire.

Previous studies hardly focused on BIM for CLM, with far too many on BIM for quantity surveying, sustainability, and generation of project programmes. Therefore, this work is relevant as it furthers research in an area where knowledge about of BIM for CLM is still very sketchy. The findings add value to existing research and have the potential to lead to changes in practices, especially considering that the study revealed that the adoption of BIM for CLM can lead to a significant improvement in performance of project delivery and elimination of waste, which is of interest to practitioners.

Due to its qualitative nature and small sample size, this investigation only serves as a foundation for further research into this particular topic. As detailed within the methodology section, the research methods were selected due to their suitability in establishing a particular situation, identifying problems, and discovering new initiatives.

Author Contributions: K.W. and F.H.A. conceived the review outline. K.W. developed and conducted qualitative interviews. M.B.M. and C.P. designed the questionnaire and analysed the quantitative data. G.E.N. contributed to conducting the literature review. All authors discussed, reviewed and contributed to the final manuscript. All authors have read and agreed to the published version of the manuscript.

Funding: This research received no external funding.

Institutional Review Board Statement: Not applicable.

Informed Consent Statement: Not applicable.

Data Availability Statement: Not applicable.

Conflicts of Interest: The authors declare no conflict of interest.

\section{References}

1. Chapman, I. The Right Information at the Right Time. AEC Magazine. 2013. Available online: http://www.aecmag.com/ comment-mainmenu-36/575-the-right-information-at-the-right-time (accessed on 13 April 2021).

2. Foy, A. Right Information. Right Person. Right Time, LinkedIn Articles. 2016. Available online: https://www.linkedin.com/ pulse/right-information-person-time-andrew-foy (accessed on 15 August 2019).

3. British Standards Institution. BS 1192-2:2013-Collaborative Production of Architectural, Engineering and Construction Information. Code of Practice; British Standards Institution, BSI Standards Ltd.: London, UK, 2013.

4. BIS. Construction 2025; HM Government Department for Business, Innovation and Skills: London, UK, 2013 ; pp. 5-62.

5. Waterhouse, R. National BIM Report 2014; RIBA Enterprises Ltd.: London, UK, 2014; p. 3.

6. Malleson, A. BIM Survey: Summary of Findings; NBS National BIM Report 2017; RIBA Enterprises Ltd.: London, UK, 2017; pp. 10-26.

7. van Ee, T. Construction Logistics Management (CLM) Construction Logistics Management (CLM). Master's Thesis, University of Twente, Enschede, The Netherlands, 2020. 
8. Agapiou, A.; Clausen, L.E.; Flanagan, R.; Norman, G.; Notman, D. The role of logistics in the materials flow process. Constr. Manag. Econ. 1998, 16, 131-137. [CrossRef]

9. Harker, A.; Allcorn, W.; Taylor, D. Material Logistics Plan Good Practice Guidance; Waste \& Resources Action Programme: Banbury, UK, 2007; pp. 7-62.

10. Browne, M. The Challenge of Construction Logistics. In Supply Chain Management and Logistics in Construction: Delivering Tomorrow's Built Environment; Kogan Page: Philadelphia, PA, USA, 2015; pp. 9-24.

11. Nolz, P.C. Optimizing construction schedules and material deliveries in city logistics: A case study from the building industry. Flex. Serv. Manuf. J. 2020. [CrossRef]

12. Magill, L.G.; Jafarifar, N.; Watson, A.; Omotayo, T. 4D BIM integrated construction supply chain logistics to optimise on-site production. Int. J. Constr. Manag. 2020. [CrossRef]

13. Munir, M.; Kiviniemi, A.; Jones, S.W.; Finnegan, S. BIM-based Operational Information Requirements for Asset Owners. Archit. Eng. Des. Manag. J. 2020, 16, 100-114. [CrossRef]

14. Sullivan, G.; Barthorpe, S.; Robbins, S. Managing Construction Logistics; Wiley-Blackwell: Chichester, UK, 2011.

15. Sobotka, A.; Czarnigowska, A.; Stefaniak, K. Logistics of construction projects. Found. Civ. Environ. Eng. 2005, 6, $203-216$.

16. Garbett, J.; Thomas Hartley, T.; Heesom, D. A multi-user collaborative BIM-AR system to support design and construction. Autom. Constr. 2021, 122, 103487. [CrossRef]

17. Guerra, B.C.; Leite, F.; Faust, K.M. 4D-BIM to enhance construction waste reuse and recycle planning: Case studies on concrete and drywall waste streams. Waste Manag. 2020, 116, 79-90. [CrossRef]

18. The Chartered Institute of Logistics and Transport. The Royal Charter. 2019. Available online: https://www.ciltuk.org.uk/ AboutUs/InstituteStructure/Governance/TheRoyalCharter.aspx (accessed on 12 September 2019).

19. Akinci, B.; Fischer, M.; Zabelle, T. Proactive Approach for Reducing Non-Value Adding Activities Due to Time-Space Conflicts. In Proceedings of the 6th Annual Conference of the International Group for Lean Construction (IGLC-6), Guaruja, Brazil, 13-15 August 1998.

20. Guerlain, C.; Renault, S.; Ferrero, F.; Faye, S. Decision Support Systems for Smarter and Sustainable Logistics of Construction Sites. Sustainability 2019, 11, 2762. [CrossRef]

21. Bortolini, R.; Shigaki, J.S.; Formoso, C.T. Site Logistic Planning and Control Using 4D Modelling: A Study in a Lean Car Factory Building Site. In Proceedings of the 23rd Annual Conference of the International Group for Lean Construction, Perth, Australia, 28-31 July 2015; pp. 361-370.

22. Government Statistical Service. UK Statistics on Waste; Statistical Notice 15.12.2015; HM Government Department For Environment, Food and Rural Affairs: London, UK, 2015; pp. 4-5.

23. WRAP. Reducing Material Wastage in Construction; Waste \& Resources Action Programme: Banbury, UK, 2007 ; pp. 1-12.

24. Ajayi, S.O.; Oyedele, L.O.; Bilal, M.; Akinade, O.O.; Alaka, H.A.; Owolabi, H.A. Critical management practices influencing on-site waste minimization inconstruction projects. Waste Manag. 2017, 59, 330-339. [CrossRef]

25. Johansson, E. Finding and Reducing Obstacles for Implementing New Logistics Systems in the Construction Industry. Master's Thesis, Karlstad Business School, Karlstad University, Karlstad, Sweden, 2013; p. 7.

26. Thomas Ng, S.; Fang, Y.; Ugwu, O.O. Modelling construction material logistics system with stochastic Petri nets. Constr. Innov. 2008, 8, 46-60.

27. Robbins, S. Effective Management of a Construction Project Supply Chain. In Supply Chain Management and Logistics in Construction: Delivering Tomorrow's Built Environment; Kogan Page: Philadelphia, PA, USA, 2015; pp. 62-75.

28. Waddell, M. Resource Efficiency Benefits of Effective Construction Logistics. In Supply Chain Management and Logistics in Construction: Delivering Tomorrow's Built Environment; Kogan Page: Philadelphia, PA, USA, 2015; pp. 139-158.

29. Transport for London. The Directory of London Construction Consolidation Centres; Transport for London (TfL): London, UK, 2016; pp. 3-15.

30. Whitlock, K.; Abanda, F.H.; Manjia, M.B.; Pettang, C.; Nkeng, G.E. BIM for Construction Site Logistics Management. J. Eng. Proj. Prod. Manag. 2018, 8, 47-55. [CrossRef]

31. Reddy, K.P. BIM for Building Owners and Developers: Making a Business Case for Using BIM on Projects; John Wiley \& Sons: Hoboken, NJ, USA, 2011.

32. Harvard. Harvard University Construction Management Council: BIM Uses Guide. 2019, pp. 1-12. Available online: https: / / home.planningoffice.harvard.edu (accessed on 19 September 2019).

33. Hardin, B.; McCool, D. BIM and Construction Management: Proven Tools, Methods, and Workflows; John Wiley \& Sons: Indianapolis, IN, USA, 2015; pp. 188-190.

34. Higgins, S.; Trevail, J.; Teglown, S. Dynamo. 2018. Available online: https://library.myebook.com/UBM/architecturaltechnology-journal-128-winter-2018-19/1521/\#page/27 (accessed on 14 April 2021).

35. Gebru, H.M.; Staub-French, S. Leveraging data to visualize and assess space planning compliance. In Proceedings of the CSCE Annual Conference Growing with Youth-Croître Avec les Jeunes, Laval (Greater Montreal), QC, Canada, 12-15 June 2019.

36. UNIFI. Construction Logistics Planning with UNIFI. 2019. Available online: https:// unifilabs.com/construction-site-logisticsplanning-with-unifi/ (accessed on 14 April 2021).

37. Moon, D.; Chung, S.; Kwon, S.; Seo, J.; Shin, J. Comparison and utilization of point cloud generated from photogrammetry and laser scanning: 3D world model for smart heavy equipment planning. Autom. Constr. 2019, 98, 322-331. [CrossRef] 
38. Zhang, J.P.; Ma, Z.Y.; Pu, C. 4D Visualisation of Construction Site Management. In Proceedings of the 5th International Conference on Information Visualisation, London, UK, 25-27 July 2001; pp. 382-387. [CrossRef]

39. Hitech 4D Construction Scheduling, Hitech CAD Services. 2019. Available online: https://www.hitechcaddservices.com/bim/ $4 \mathrm{~d} /$ (accessed on 20 September 2019).

40. Kumar, S.; Cheng, J. A BIM-based automated site layout planning framework for congested construction sites. Autom. Constr. 2015, 59, 24-37. [CrossRef]

41. Demchak, G.; Dzambazova, T.; Krygiel, E. Mastering Revit Architecture 2010; John Wiley \& Sons: Indianapolis, IN, USA, 2011; pp. 1-14.

42. Amor, R.; Dimyadi, J. The promise of automated compliance checking. Dev. Built Environ. 2021, 5, 100039. [CrossRef]

43. Irizarry, J.; Karan, E.P.; Jalaei, F. Integrating BIM and GIS to improve the visual monitoring of construction supply chain management. Autom. Constr. 2013, 31, 241-254. [CrossRef]

44. Chen, Q.; de Soto, B.G.; Adey, B.T. Supplier-contractor coordination approach to managing demand fluctuations of ready-mix concrete. Autom. Constr. 2021, 21, 103423. [CrossRef]

45. Rebolj, D.; Babič, N.C.; Magdič, A.; Podbreznik, P.; Pšunder, M. Automated Construction Activity Monitoring System. Adv. Eng. Inform. 2008, 22, 493-503. [CrossRef]

46. Azhar, S. Building Information Modelling (BIM): Trends, Benefits, Risks, and Challenges for the AEC Industry. In Leadership and Management in Engineering; American Society of Civil Engineers: Reston, VA, USA, 2011; pp. 241-252.

47. Martins, S.S.; Evangelista, A.C.J.; Hammad, A.W.A.; Tam, V.W.Y.; Haddad, A. Evaluation of 4D BIM tools applicability in construction planning efficiency. Int. J. Constr. Manag. 2020. [CrossRef]

48. Vigneault, M.A.; Boton, C.; Chong, H.Y.; Cooper-Cooke, B. An Innovative Framework of 5D BIM Solutions for Construction Cost Management: A Systematic Review. Arch. Comput. Methods Eng. 2020, 27, 1013-1030. [CrossRef]

49. Lee, J.; Kim, J. BIM-Based 4D Simulation to Improve Module Manufacturing Productivity for Sustainable Building Projects. Sustainability 2017, 9, 426. [CrossRef]

50. BIS. UK Construction: An Economic Analysis of the Sector; HM Government Department for Business, Innovation and Skills: London, UK, 2013; p. 7.

51. Abanda, F.H.; Tah, J.H.M.; Cheung, F.K.T. BIM in off-site manufacturing for buildings. J. Build. Eng. 2017, 14, 89-102. [CrossRef]

52. Eastman, C.; Teicholz, P.; Sacks, R.; Liston, K. BIM Handbook: A Guide to Building Information Modeling for Owners, Managers, Designers, Engineers and Contractors; John Wiley \& Sons: Hoboken, NJ, USA, 2011; pp. 322-326.

53. Lundesjo, G. Consolidation Centres in Construction Logistics. In Supply Chain Management and Logistics in Construction: Delivering Tomorrow's Built Environment; Kogan Page: Philadelphia, PA, USA, 2015; pp. 225-242.

54. Si, T.; Li, H.X.; Hosseini, M.R.; Ji, Y.; Liu, C. A Solution to Just-in-Time Delivery for Off-Site Construction: A Conceptual Model. In Proceedings of the Construction Research Congress 2020, Tempe, AZ, USA, 3-8 March 2020.

55. Bortolini, R.; Formoso, C.T.; Viana, D.D. Site logistics planning and control for engineer-to-order prefabricated building systems using BIM 4D modelling. Autom. Constr. 2019, 98, 248-264. [CrossRef]

56. Cookson, G.; Pishue, B. INRIX Global Traffic Scorecard; INRIX Research: London, UK, 2017.

57. Carmona, M. London's local high streets: The problems, potential and complexities of mixed street corridors. Prog. Plan. 2015, 100, 1-84. [CrossRef]

58. Croydon Council. A Practical Guide to Drafting a Construction Logistics Plan. 2012. Available online: https://www.croydon.gov. $\mathrm{uk}$ /planningandregeneration/regeneration/construction-logistics-in-croydon (accessed on 21 July 2019).

59. Transport for London. Construction Logistics Plan Guidance for Developers; Transport for London (TfL): London, UK, 2013 ; p. 3.

60. Fellows, R.F.; Liu, A. Research Methods for Construction, 4th ed.; Wiley-Blackwell: Oxford, UK, 2015.

61. Soliman, D.F. 3D Subdivision. 2010. Available online: https://blog.cafebim.com/3d-subdivision-part-1-of-3-646f6541d849 (accessed on 16 September 2019).

62. Marefat, A.; Toosi, H.; Hasankhanlo, R.M. A BIM approach for construction safety: Applications, barriers and solutions. Eng. Constr. Archit. Manag. 2019, 26, 1855-1877. [CrossRef]

63. Vilventhan, A.; Razin, S.; Rajadurai, R. 4D BIM models for smart utility relocation management in urban infrastructure projects. Facilities 2020, 39, 50-63. [CrossRef] 